Disponível em:

http://editora.unoesc.edu.br/index.php/race

RACE, Joaçaba, v. 16, n. 2, p. 523-546, maio/ago. 2017

\title{
REPUTAÇÃO GERA VALOR PARA OS ACIONISTAS? UMA ANÁLISE NAS EMPRESAS BRASILEIRAS
}

Does reputation create value for shareholders? An analysis in brazilian companies

\begin{abstract}
Alan Diógenes Góis
E-mail: alandgois@usp.br

Mestre em Administração e Controladoria pela Universidade Federal do Ceará; Doutorando (Bolsista) em Controladoria e Contabilidade pela Universidade de São

Paulo.
\end{abstract}

Márcia Martins Mendes De Luca

E-mail: marciammdeluca@gmail.com

Doutora em Controladoria e Contabilidade pela Universidade de São Paulo; Mestre em Controladoria e Contabilidade pela Universidade de São Paulo; Professora na Universidade Federal do Ceará. Endereço para contato: Avenida da Universidade, 2853, Benfica, 60020-180, Fortaleza, Ceará, Brasil.

\section{Gerlando Augusto Sampaio Franco de Lima}

E-mail: gerlando@usp.br

Pós-doutor em Contabilidade pela University of Illinois at Urbana-Champaign, Illinois; Doutor em Controladoria e Contabilidade pela Universidade de São Paulo; Livre-Docente e Professor Associado no Departamento de Contabilidade da Faculdade de Economia, Administração e Contabilidade da Universidade de São Paulo.

Alessandra Carvalho de Vasconcelos

E-mail: alevasconcelos.ufc@gmail.com

Doutora em Engenharia de Produção pela Universidade Federal de Santa Catarina; Mestre em Ciências Contábeis pela Fundação Universidade Regional de Blumenau; Professora Adjunta na Universidade Federal do Ceará.

Artigo recebido em 19 de fevereiro de 2017. Aceito em 07 de abril de 2017. 


\section{Resumo}

Estudos apontam que a partir dos sinais emitidos pela empresa ao mercado se constrói a sua reputação, considerado um recurso estratégico capaz de gerar vantagem competitiva. Nesse contexto, neste estudo teve-se o objetivo geral de investigar a relação entre a reputação corporativa e a criação de valor nas empresas de capital aberto listadas na bolsa brasileira, BM\&FBovespa. Para a construção da reputação, foram analisados cinco sinais de reputação corporativa no período de 2010 a 2012, e a criação de valor se refere ao exercício de 2013. Considerando-se a amostra, verificou-se que a reputação corporativa influencia positivamente a criação de valor. Além disso, o endividamento, a idade e o setor de impacto ambiental apresentaram relação com a criação de valor. Portanto, conclui-se que a reputação corporativa é um recurso estratégico gerado por meio de sinais emitidos para o mercado, conforme preceitos da Teoria da Sinalização, os quais, quando percebidos pelos diversos stakeholders, refletem em vantagem competitiva, sendo capazes de influenciar a criação de valor das empresas, de acordo com os pressupostos da Visão Baseada em Recursos.

Palavras-chave: Reputação corporativa. Criação de valor. Teoria da Sinalização. Visão Baseada em Recursos.

\section{Abstract}

Studies point out that from the signals issued by the company to the market is built your reputation, considered a strategic resource capable of generating competitive advantage. In this context, the study aims at investigating the relationship between corporate reputation and value creation in public companies listed in the Brazilian Stock Exchange, BM\&FBovespa. To build the reputation, five corporate reputation signs were analyzed among the period 20102012, and the value creation refers to the year 2013. Considering the sample, it was found that corporate reputation influences positively the value creation. In addition, leverage, age and the environmental impact of industry were related to value creation. Therefore, it was concluded that corporate reputation is a strategic resource generated through signals emitted to the market, according to precepts of the Signaling Theory, which, when perceived by several stakeholders, reflected in competitive advantage, being able to influence the value creation of companies, according to the assumptions of Resource-Based View.

Keywords: Corporate reputation. Value creation. Signaling Theory. Resource-Based View.

\section{INTRODUÇÃO}

Em um ambiente de competitividade no mercado e mais exigência dos consumidores, a cada dia se torna mais difícil para as empresas maximizarem os resultados e a sua riqueza. Para tanto, recorrem a diversas atitudes, capazes de diferenciá-las 
das demais. Essas ações têm o intuito de atingir os diversos stakeholders, pois eles que atribuirão, por intermédio de experiências diretas e/ou indiretas, características distintas às empresas, tornando-as diferentes umas das outras (DALMÁCIO et al., 2013; GOTSI; WILSON, 2001). Nesse contexto, a disponibilização de informações de maior qualidade reduz a assimetria informacional (BERGH; GIBBONS, 2011) e pode ser considerada uma das principais ferramentas utilizadas para se fazer perceber pelos stakeholders.

Com base na Teoria da Sinalização, essas informações são denominadas sinais, que, segundo Spence (1973), representam atividades ou atributos os quais, planejados ou acidentais, alteram crenças ou transmitem informações para outros, sendo uma fonte de comunicação confiável para os stakeholders (SPENCE, 2002). Por sua vez, a emissão de sinais pelas empresas, ao longo do tempo, é convertida em determinado prestígio dado pelos stakeholders por meio de suas percepções, constituindo-se na sua reputação corporativa (FOMBRUN; SHANLEY, 1990; THOMAZ; BRITO, 2010).

Zabala et al. (2005) definem a reputação como o prestígio ou o reconhecimento dos stakeholders de que uma empresa executa boas práticas em sua gestão de recursos. Para Roberts e Dowling (2002), a reputação corporativa consiste no conjunto de atributos organizacionais, desenvolvidos ao longo do tempo, que influencia a forma como os stakeholders percebem a empresa com boa conduta corporativa.

Sob o aspecto da Visão Baseada em Recursos (VBR), a reputação é um recurso estratégico que cria heterogeneidade, gera valor e é difícil de ser duplicada, comprada ou transferida (BERGH et al., 2010; RINDOVA; WILLIAMSON; PETKOVA, 2010; TOMS, 2002). Para tanto, Barney (1991) assevera que a inserção de uma estratégia empresarial diferente das estratégias praticadas pela concorrência, e incapaz de ser repetida, gera uma vantagem competitiva e cria valor para os acionistas. Destarte, a reputação corporativa é fonte de vantagem competitiva e criação de valor, mensurado por meio de diversos indicadores empresariais (CAIXETA et al., 2011; FOMBRUN; SHANLEY, 1990; ROBERTS; DOWLING, 2002; THOMAZ; BRITO, 2010).

Dessa forma, considerando-se a importância do tema para as empresas, para fins deste estudo, a reputação corporativa reúne as diversas perspectivas que os stakeholders possuem da empresa (com suporte na Teoria da Sinalização), atribuindo-lhe a característica de um recurso estratégico capaz de gerar visibilidade, credibilidade e valor para as organizações que a possuem (sob os preceitos da VBR). Assim, com base na literatura, neste estudo adotam-se como sinais construtivos da reputação corporativa o disclosure socioambiental, a adoção de melhores práticas de governança corporativa, a inovação, a internacionalização e a reputação do diretor executivo. 
Considerando a definição de reputação corporativa e a sua característica de ativo intangível e dos sinais que a compõem, apresenta-se o seguinte objetivo geral: investigar a relação entre a reputação corporativa e a criação de valor nas empresas de capital aberto listadas na BM\&FBovespa.

Acredita-se na contribuição desta pesquisa na medida em que se analisa o contexto das empresas listadas no mercado de capitais brasileiro, em que, segundo Lopes e Martins (2012), ocorrem problemas de assimetria informacional e imperfeições quanto à informação contábil. Desse modo, a reputação corporativa auxiliaria as empresas quanto a esses problemas, já que, por meio de uma boa reputação corporativa, as empresas obtêm credibilidade e, assim, conseguem se destacar no mercado, obtendo novos clientes, fornecedores e investidores, e esse rol de interações contribui para que essas firmas alcancem desempenho superior aos de seus concorrentes. Faz-se interessante a análise das empresas listadas na BM\&FBovespa, que é uma das maiores bolsas do mundo em valor de mercado e a segunda maior das Américas; logo, a reputação das empresas listadas nessa Bolsa podem transcender o mercado doméstico brasileiro. Ressalte-se, ainda, o caráter diferencial do estudo, pois na literatura muitos estudos utilizam rankings como proxy de reputação corporativa, e a presente pesquisa desenvolve uma métrica com base em sinais que contribuem para a construção da reputação corporativa.

\section{REVISÃO DA LITERATURA}

Entre as diversas teorias que abordam a reputação corporativa, o estudo toma por base a Teoria da Sinalização e a VBR. A primeira explica como a reputação é formada, enquanto a segunda explica o que é a reputação, assim como seus reflexos para as empresas.

No contexto organizacional, a Teoria da Sinalização tem por base a redução da assimetria informacional, na qual os gestores detêm informações sobre as empresas que os investidores não conhecem (DALMÁCIO et al., 2013; VIEIRA; NOVO, 2010). Para reduzir a assimetria informacional, as empresas disponibilizam mais informações para seus stakeholders (BERGH; GIBBONS, 2011), denominadas sinais, que, segundo Spence (1973), são atividades ou atributos que, planejados ou acidentais, alteram crenças ou transmitem informações para outros, sendo uma fonte de comunicação confiável para os stakeholders (SPENCE, 2002).

Destarte, a sinalização se torna essencial em um ambiente com assimetria de informações, cujos participantes procuram por sinais que lhes indiquem as me- 
lhores decisões a serem tomadas (DALMÁCIO et al., 2013; MATOS, 2001). A assimetria informacional pode ser reduzida se a empresa oferecer um número maior de informações do que outras, sugerindo, assim, que os gestores de companhias de alta qualidade desejam se diferenciar de empresas com baixa qualidade, por meio de sinais (KLANN; BEUREN, 2011). Nessa perspectiva, Dainelli, Bini e Giunta (2013) postulam que as empresas mais lucrativas sinalizam sua força competitiva, ampliando seu disclosure por meio de melhores informações para o mercado.

Essas empresas com alta qualidade seriam percebidas pelos stakeholders, os quais, portanto, atribuiriam-lhes melhor reputação, com base nos sinais recebidos. Bergh e Gibbons (2011) reforçam essa afirmação, admitindo que a reputação reduz a assimetria informacional, fornecendo insights sobre qualidade e integridade da empresa.

Por sua vez, a VBR está relacionada com a estratégia da empresa (LOCKETT; THOMPSON; MORGENSTERN, 2009), visto que a estratégia pode ser vista como a escolha de uma posição, na qual a empresa se coloca em um ambiente competitivo em busca de alcançar seus objetivos (DAL-SOTO; SANTOS, 2004). A análise desse ambiente competitivo deve ser focada em fatores internos à firma, que sejam particulares, difíceis de ser copiados ou imitados; destarte, fonte de vantagem competitiva (BARNEY, 1991).

A reputação corporativa é, portanto, um dos recursos estratégicos das organizações que deve ser observado e monitorado, e obedece aos pressupostos da VBR, pois é valiosa, rara e difícil de ser copiada ou imitada (BOYD; BERGH; KETCHEN JUNIOR, 2010; CARDOSO et al., 2013).

Fundamentada nas duas teorias aqui expostas - a Teoria da Sinalização e a VBR -, a reputação é definida como um recurso estratégico que gera vantagem competitiva, formado a partir da percepção dos stakeholders por meio dos sinais emitidos pela empresa. Dessa forma, as empresas tomam determinadas atitudes que são evidenciadas - sinais - para o mercado, e este, por sua vez, assimila as informações e concede prestígio para determinada empresa, compondo, assim, a sua reputação.

A partir dos sinais emitidos pela empresa ao mercado, constrói-se um produto de avaliação moral dos stakeholders - a reputação corporativa (BARNETT; JERMIER; LAFFERTY, 2006), que cria valor para os acionistas. Para este estudo, com base na literatura, são considerados responsáveis pela construção da reputação corporativa e consequente criação de valor: o disclosure socioambiental, a adoção de melhores práticas de governança corporativa, a inovação, a internacionalização e a reputação do diretor executivo. 
Quanto ao primeiro sinal, ou seja, o disclosure socioambiental, vale mencionar que os stakeholders pressionam cada vez mais as empresas para divulgar informações sobre o cariz sustentável de suas atividades (ALMEIDA-SANTOS et al., 2012), e, quanto mais ações sustentáveis são realizadas pelas organizações e seus resultados forem evidenciados, mais bem- vistas são essas empresas (CRUZ; LIMA, 2010; MICHELON, 2011; ROVER et al., 2008).

A adoção de melhores práticas de governança corporativa, segundo sinal considerado no estudo, tem o intuito de reduzir as possíveis ações oportunísticas por parte dos gestores e acionistas controladores (SILVA; NARDI; PIMENTA JUNIOR, 2012), assegurando, assim, o bem-estar de todos os stakeholders envolvidos com as empresas - principalmente os acionistas minoritários. Dessa forma, a partir da adoção de boas práticas de governança surge o sentimento de confiança que se converte em reputação corporativa (DALMÁCIO et al., 2013; GORGA, 2004; NARDI; NAKAO, 2008).

No que se refere ao terceiro sinal, destaca-se que as empresas investem em inovação com o objetivo de auferir vantagem competitiva e, como consequência, a criação de valor (SANTOS; VASCONCELOS; DE LUCA, 2013; TEH; KAYO; KIMURA, 2008). Desse modo, a inovação busca destacar as empresas perante as demais, e quando os investimentos em inovação são concretizados, elas se tornam atraentes pela capacidade de criar valor (TEH; KAYO; KIMURA, 2008).

Ainda sob a perspectiva de obter vantagem competitiva, as empresas chegam a um ponto em que o mercado doméstico não é suficiente para as suas atividades. Por conseguinte, a eficiência em outros mercados pode proporcionar retornos superiores (MACHADO; CARVALHO, 2013; SPERS; WRIGHT, 2013; STAL, 2010). Portanto, assim como a inovação, a internacionalização é uma das estratégias das empresas que gera prestígio quando bem-sucedida, sendo, portanto, considerada sinal neste estudo.

O último sinal construtivo da reputação corporativa objeto deste estudo é a reputação do diretor executivo (ou reputação da gestão), representada pela combinação complexa das mais importantes características pessoais e realizações, assim como pelo comportamento demonstrado e pelas imagens projetadas durante algum lapso temporal (HOCHWARTER et al., 2007). Essa reputação serve para reduzir a incerteza em relação ao comportamento futuro esperado do indivíduo ou entidade, sendo tal definição atrelada ao conceito de confiança (HALL et al., 2004). Assim, os gestores com melhor reputação tendem a garantir credibilidade às empresas, tornando-as distintas no mercado.

Diante do exposto, pode-se afirmar que as variáveis disclosure socioambiental, adoção de melhores práticas de governança corporativa, inovação, internaciona- 
lização e reputação do diretor executivo são sinais que colaboram na construção da reputação corporativa. Quando positivos, esses sinais geram boa reputação, que fortalece a atratividade da organização, atrai e retém colaboradores, além de atrair novas fontes de capital financeiro, e, dessa forma, as empresas com reputação positiva são menos propensas a enfrentarem situações de risco (VAN RIEL; FOMBRUN, 2007). A reputação também é considerada importante porque é vista como uma solução para a assimetria informacional (MELO; GARRIDO-MORGADO, 2012).

Van Riel e Fombrun (2007) afirmam ainda que a reputação é importante tanto para os donos da reputação quanto para os sujeitos que têm essa reputação armazenada em sua memória no longo prazo, pois, quando uma empresa possui uma reputação favorável, considera-se a transmissão de sua reputação positiva uma condição prévia essencial para o estabelecimento de uma relação comercial com seus stakeholders.

De acordo com Brito (2005, p. 121), a reputação corporativa é "vista como um recurso, fonte potencial de vantagem competitiva, já que ela cria heterogeneidade entre as empresas, gera valor aos stakeholders, é difícil de ser duplicada, comprada ou transferida e pode criar uma reserva de mercado para a empresa.” A afirmação de que a reputação está associada à vantagem competitiva é corroborada por Inglis, Morley e Sammut (2006), Melo e Garrido-Morgado (2012) e Roberts e Dowling (2002).

Com base na literatura já mencionada, e considerando-se que as empresas com boa reputação corporativa são capazes de conseguir vantagem competitiva e criar valor (BRITO, 2005; CARDOSO et al., 2013; FOMBRUN; SHANLEY, 1990; ROBERTS; DOWLING, 2002; SÁNCHEZ; SOTORRÍO, 2007; THOMAZ; BRITO, 2010; TISCHER; HILDEBRANDT, 2013), desenvolveu-se a seguinte hipótese: $\mathrm{H}_{1}$ : a reputação corporativa influencia positivamente a criação de valor nas empresas.

Dessa forma, com base na literatura pesquisada, neste estudo propõe-se o modelo teórico apresentado no Diagrama 1 para se investigar a relação entre a reputação corporativa e a criação de valor para os acionistas.

Diagrama 1 - Modelo teórico da pesquisa

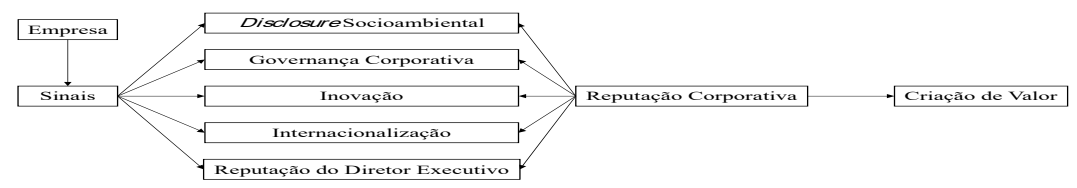

Fonte: os autores. 
No Diagrama 1 pode-se observar que a reputação corporativa, como um recurso estratégico, é capaz de gerar vantagem competitiva e criar valor a partir da percepção do mercado (stakeholders), com base nos sinais emitidos pelas empresas, que neste estudo são representados por disclosure socioambiental, adoção de melhores práticas de governança corporativa, inovação, internacionalização e reputação do diretor executivo.

\section{MÉTODO DE PESQUISA}

A pesquisa se caracteriza como descritiva, pois identifica e obtém informações sobre as características de um problema específico (COLLIS; HUSSEY, 2005). Quanto à abordagem, é considerada quantitativa, porquanto usa os dados para testar hipóteses com base na medição numérica, adotando a análise estatística para estabelecer padrões de comportamento (SAMPIERI; COLLADO; LÚCIO, 2013).

A população da pesquisa compreende todas as empresas listadas na BM\&FBovespa em 21 de março de 2014, totalizando 525 companhias de capital aberto. Para a definição da amostra, foram selecionadas as 126 empresas que apresentaram as informações necessárias para a mensuração da reputação corporativa.

A fonte da coleta dos dados referente aos sinais construtivos da reputação corporativa considerados na pesquisa é secundária. Os dados referentes ao disclosure socioambiental, à adoção de melhores práticas de governança corporativa, à inovação, à internacionalização e à reputação do diretor executivo foram extraídos dos Relatórios Anuais e/ou de Sustentabilidade, Formulários de Referência, Demonstrações Financeiras Padronizadas, Notas Explicativas às demonstrações financeiras referentes aos exercícios sociais findos em 31 de dezembro de 2010 e 31 de dezembro de 2012. Quanto à criação de valor, os dados para a construção dos indicadores foram obtidos na base de dados Economatica ${ }^{\circledR}$ e no portal eletrônico Damodaran On-line referentes ao exercício findo em 31 de dezembro de 2013. As informações adicionais, utilizadas na forma de variáveis de controle, como tamanho, idade, endividamento, risco, rotatividade de empregados e setor de impacto ambiental, referem-se ao exercício de 2013 e foram obtidas na base de dados Economatica ${ }^{\circledR}$ e no Formulário de Referência. O Quadro 1 apresenta um resumo das variáveis que compõem a reputação corporativa. 
Quadro 1 - Variáveis que compõem a reputação corporativa

\begin{tabular}{|c|c|c|c|}
\hline \multicolumn{2}{|l|}{ Variável } & Operacionalização & $\begin{array}{l}\text { Fundamenta- } \\
\text { ção teórica }\end{array}$ \\
\hline $\begin{array}{l}\text { Disclosure socioam- } \\
\text { biental }\end{array}$ & DISC & $\begin{array}{l}\text { Somatório de itens socioambientais observa- } \\
\text { dos nos relatórios anuais e de sustentabilidade, } \\
\text { dividido pelo número de itens possíveis (42). }\end{array}$ & $\begin{array}{l}\text { Múrcia e Santos } \\
\text { (2009) e } \\
\text { Souza, Lunkes } \\
\text { e Uhlmann } \\
\text { (2010). }\end{array}$ \\
\hline $\begin{array}{l}\text { Adoção de melhores } \\
\text { práticas de governança } \\
\text { corporativa }\end{array}$ & GOV & $\begin{array}{l}\text { Somatório de questões sobre práticas de } \\
\text { governança, observadas nos Formulários } \\
\text { de Referência, nos Estatutos Sociais e nas } \\
\text { Demonstrações Financeiras Padronizadas } \\
\text { (Balanço Patrimonial), dividido pelo número } \\
\text { de questões possíveis (18). }\end{array}$ & $\begin{array}{l}\text { Lameira (2012) } \\
\text { e } \\
\text { Lameira et al. } \\
\text { (2011). }\end{array}$ \\
\hline Inovação & INOV & $\begin{array}{l}\text { Proporção de ativos intangíveis de inovação } \\
\text { em relação ao total de ativos intangíveis. }\end{array}$ & $\begin{array}{l}\text { Brooking } \\
\text { (1996), } \\
\text { Kayo et al. } \\
\text { (2006) e } \\
\text { Lev (2001). }\end{array}$ \\
\hline Internacionalização & INTER & $\begin{array}{l}\text { Quociente entre o lucro líquido e as receitas } \\
\text { provindas do exterior. }\end{array}$ & $\begin{array}{l}\text { Santos, Vascon- } \\
\text { celos e De Luca } \\
\text { (2013). }\end{array}$ \\
\hline $\begin{array}{l}\text { Reputação do diretor } \\
\text { executivo }\end{array}$ & $\mathrm{RDE}$ & $\begin{array}{l}\text { Soma aritmética simples das pontuações do } \\
\text { diretor executivo para os seguintes atributos: } \\
\text { qualificação, associação profissional, manda- } \\
\text { to e experiência anterior. }\end{array}$ & $\begin{array}{l}\text { Niap e Taylor } \\
\text { (2012). }\end{array}$ \\
\hline
\end{tabular}

Fonte: os autores.

Com base nas informações do Quadro 1, a reputação corporativa (REP) é mensurada pela variação entre a média dos sinais dos anos 2012 e 2010.

A criação de valor é mensurada a partir do Economic Value Added (EVA) ${ }^{\circledR}$, que considera o lucro líquido (LL), o patrimônio líquido e o custo de capital próprio (CC). O custo de capital próprio, estimado por meio do Capital Asset Pricing Model $(C A P M)$, é calculado com base na taxa livre de risco (RF), no beta de mercado do ativo $(\beta)$, no retorno da carteira de mercado (RM) e no prêmio pelo risco do país (RP), em que o retorno da carteira de mercado menos a taxa livre de risco ( $R M-R F)$ é igual ao prêmio de risco de mercado (ALBANEZ, 2012). Segundo Albanez (2012), o custo de capital próprio é mensurado conforme mostra a Equação 1.

$$
\mathrm{CC}_{\mathrm{i}}=\mathrm{RF}+\beta_{\mathrm{i}} \times(\mathrm{RM}-\mathrm{RF})+\mathrm{RP}
$$

A operacionalização das variáveis que compõem o custo de capital próprio é descrita no Quadro 2, com base no estudo de Albanez (2012). 
Quadro 2 - Variáveis que compõem o custo de capital próprio

\begin{tabular}{|c|c|c|c|}
\hline \multicolumn{2}{|l|}{ Variável } & \multirow{2}{*}{$\begin{array}{l}\text { Operacionalização } \\
\text { Taxa de remuneração nominal do título do tesouro } \\
\text { norte-americano (T-Bond) com maturidade de } 10 \\
\text { anos como taxa livre de risco. }\end{array}$} & \multirow{2}{*}{$\begin{array}{r}\text { Fonte de dados } \\
\text { Damodaran On-line }\end{array}$} \\
\hline $\begin{array}{l}\text { Taxa livre de } \\
\text { risco }\end{array}$ & $\mathrm{RF}$ & & \\
\hline $\begin{array}{l}\text { Beta de mercado } \\
\text { do ativo }\end{array}$ & $\beta$ & $\begin{array}{l}\text { Para obter o beta alavancado: classificação de } \\
\text { cada empresa em um dos setores americanos; } \\
\text { obtenção do beta desalavancado médio do setor } \\
\text { americano de referência para cada empresa da } \\
\text { amostra; alavancagem do beta obtido no passo “2” } \\
\text { pela alavancagem de cada empresa brasileira, da } \\
\text { seguinte forma: BetaAlav = BetaDesalav x [1 + } \\
\text { PO/PL) x (1 - IR)], em que BetaAlav é Beta ala- } \\
\text { vancado; BetaDesalav é Beta desalavancado; PO } \\
\text { é Passivo Oneroso; PL é patrimônio líquido e IR } \\
\text { é alíquota de impostos aproximada em 34\% (25\% } \\
\text { de imposto de renda e 9\% de contribuição social). }\end{array}$ & $\begin{array}{l}\text { Damodaran On-line e } \\
\text { Economatica }{ }^{\circledR}\end{array}$ \\
\hline $\begin{array}{l}\text { Prêmio de risco } \\
\text { de mercado }\end{array}$ & $\begin{array}{l}\text { RM- } \\
\text {-RF }\end{array}$ & $\begin{array}{l}\text { Média móvel histórica do retorno ex-post da } \\
\text { carteira de mercado S\&P500 menos o retorno do } \\
\text { T-Bond, considerando um longo período de tempo } \\
\text { (1928-ano atual). }\end{array}$ & Damodaran On-line \\
\hline Risco país & $\mathrm{RP}$ & $\begin{array}{l}\text { Índice de Títulos de Mercados Emergentes - } \\
\text { Brasil (Embi+Br), desenvolvido pelo banco JP } \\
\text { Morgan. }\end{array}$ & Acionista.com.br \\
\hline
\end{tabular}

Fonte: adaptado de Albanez (2012).

Com base nos estudos de Ehrbar (1999), Santos e Watanabe (2005) e Cerqueira, Soares e David (2009), o $E V A^{\circledR}$ é representado pela diferença entre o lucro líquido e a relação patrimônio líquido e custo de capital. Contudo, para o estudo, o $E V A^{\circledR}$ é transformado em um índice conforme a Equação 2.

$$
\mathrm{EVA}=[\mathrm{LL}-(\mathrm{PL} \times \mathrm{CC})]
$$

Para atender ao objetivo e verificar a hipótese da pesquisa, aplicou-se a Regressão Linear Múltipla, sendo variável dependente a criação de valor (EVA) e variável independente a reputação corporativa (REP), além das variáveis de controle - rotatividade dos empregados (ROT), endividamento (END), risco (RIS), idade (IDA), tamanho (TAM) e setor de impacto ambiental (SET), como demonstrado na Equação 3.

$$
\mathrm{EVA}_{\mathrm{i}}=\beta_{0}+\beta_{1} \mathrm{REP}_{\mathrm{i}}+\beta_{2} \mathrm{ROT}_{\mathrm{i}}+\beta_{3} \mathrm{END}_{\mathrm{i}}+\beta_{4} \mathrm{RIS}_{\mathrm{i}}+\beta_{5} \mathrm{IDA}_{\mathrm{i}}+\beta_{6} \mathrm{TAM}_{\mathrm{i}}+\beta_{7} \mathrm{SET}_{\mathrm{i}}+\varepsilon_{\mathrm{i}}
$$

O Quadro 3 apresenta as variáveis utilizadas para testar a hipótese bem como a sua operacionalização e fundamentação teórica. 
Quadro 3 - Variáveis da pesquisa

\begin{tabular}{|c|c|c|c|}
\hline \multicolumn{2}{|c|}{ Variável } & \multirow[t]{2}{*}{ Operacionalização } & \multirow{2}{*}{\begin{tabular}{l}
\multicolumn{1}{c}{ Fundamentação Teórica } \\
Cerqueira, Soares e David (2009) \\
e Ehrbar (1999).
\end{tabular}} \\
\hline $\begin{array}{l}\text { Criação de } \\
\text { valor }\end{array}$ & EVA & & \\
\hline $\begin{array}{l}\text { Reputação } \\
\text { corporativa }\end{array}$ & REP & $\begin{array}{l}\mathrm{REP}_{2012}-\mathrm{REP}_{2010} \text {, } \\
\text { Em que REP é igual à média entre os cin- } \\
\text { co sinais demonstrados no Quadro } 1 .\end{array}$ & $\begin{array}{l}\text { Cardoso et al. (2013), } \\
\text { Fombrun e Shanley (1990), } \\
\text { Inglis, Morley e Sammut (2006), } \\
\text { Melo e Garrido-Morgado (2012) } \\
\text { e Roberts e Dowling (2002). }\end{array}$ \\
\hline $\begin{array}{l}\text { Rotatividade } \\
\text { dos empre- } \\
\text { gados }\end{array}$ & ROT & $\begin{array}{l}\text { Índice de rotatividade divulgado pelas } \\
\text { empresas no item } 14.1 \text { do Formulário de } \\
\text { Referência. }\end{array}$ & Hancock et al. (2013). \\
\hline $\begin{array}{l}\text { Endivida- } \\
\text { mento }\end{array}$ & END & $\begin{array}{l}\text { Quociente entre o passivo total (circu- } \\
\text { lante mais não circulante) e o patrimônio } \\
\text { líquido. }\end{array}$ & $\begin{array}{l}\text { Almeida-Santos et al. (2012), } \\
\text { Michelon (2011) e } \\
\text { Díez et al. (2010). }\end{array}$ \\
\hline Risco & RIS & $\begin{array}{l}\text { Calculado pelo Beta, que é obtido a partir } \\
\text { das oscilações da ação e do índice em cada } \\
\left.\text { um de } n \text { intervalos (Economatica }{ }^{\circledR}\right) \text {. }\end{array}$ & $\begin{array}{l}\text { Lameira (2012), } \\
\text { Dainelli, Bini e Giunta (2013) } \\
\text { Fombrun e Shanley (1990). }\end{array}$ \\
\hline Idade & IDA & $\begin{array}{l}\text { Diferença entre a data de constituição da } \\
\text { empresa (Formulário de Referência) e o } \\
\text { ano } 2013 .\end{array}$ & $\begin{array}{l}\text { Díez et al. (2010) e } \\
\text { Michelon (2011). }\end{array}$ \\
\hline Tamanho & TAM & Logaritmo natural do ativo total. & $\begin{array}{l}\text { Cardoso et al. (2013), } \\
\text { Klann e Beuren (2011), } \\
\text { Roberts e Dowling (2002) e } \\
\text { Rose e Thomsen (2004). }\end{array}$ \\
\hline $\begin{array}{l}\text { Setor de } \\
\text { impacto } \\
\text { ambiental }\end{array}$ & SET & $\begin{array}{l}\text { Variável dummy, sendo um para empresas } \\
\text { de setores de alto impacto ambiental e } 0 \\
\text { caso contrário. }\end{array}$ & Michelon (2011). \\
\hline
\end{tabular}

Fonte: os autores.

Frisa-se que, anterior à apresentação dos resultados acerca da Regressão Linear Múltipla, o estudo realiza uma estatística descritiva das variáveis, uma Análise de Correspondência entre a criação de valor e a reputação corporativa, além da Correlação de Pearson.

O tratamento dos dados (Análise de Correspondência, Correlação de Pearson e Regressão Linear Múltipla) foi realizado com o auxílio do aplicativo Stata, versão 13.

\section{RESULTADOS DA PESQUISA}

Para testar a hipótese da pesquisa e atender ao objetivo geral foi realizada a regressão linear múltipla, com base nos dados das 126 empresas da amostra. Inicial- 
mente, procedeu-se à análise da estatística descritiva para verificar o comportamento dos dados, conforme a Tabela 1.

Tabela 1 - Estatística descritiva

\begin{tabular}{lrrrrrr}
\hline Variável & Observações & Mínimo & Máximo & Média & Desvio padrão & $\begin{array}{c}\text { Coeficiente de } \\
\text { variação }\end{array}$ \\
\hline EVA & 126 & $-12,091$ & 12,368 & 0,261 & 2,525 & 9,660 \\
REP & 126 & $-0,192$ & 114,408 & 2,027 & 10,687 & 5,274 \\
ROT & 126 & 0,000 & 0,650 & 0,140 & 0,141 & 1,010 \\
END & 126 & $-6,737$ & 30,720 & 2,937 & 4,157 & 1,415 \\
RIS & 126 & $-0,293$ & 2,480 & 0,868 & 0,452 & 0,520 \\
IDA & 126 & 3 & 205 & 41,405 & 30,971 & 0,748 \\
TAM & 126 & 13,124 & 20,989 & 15,987 & 1,543 & 0,097 \\
\hline Fonte: os autores. & & & & & &
\end{tabular}

Pode-se verificar que a criação de valor (EVA) possui uma média positiva, demonstrando que, em média, as empresas criam valor no exercício findo em 31 de dezembro de 2013, e que as empresas possuem uma alta dispersão entre si. Isso também se verifica para a variável a reputação (REP), justificado pelo fato de que a reputação gera heterogeneidade entre as empresas (BARNEY, 1991).

Quanto às variáveis de controle, verifica-se que as empresas possuem baixa (14\%) rotatividade (ROT), variando entre 0\% e 65\%; possuem endividamento (END) médio de 2,93; e baixo risco (RIS), com média de 0,87. Em relação à idade (IDA), a amostra possui empresas jovens (três anos) e empresas mais antigas (205 anos), tendo em média 41 anos. Quanto ao tamanho (TAM), percebe-se uma homogeneidade nos dados, visto que, em média, os ativos totais dessas empresas somam aproximadamente $\mathrm{R} \$ 8.771 .338,72$, em milhares.

Com base nas variáveis de interesse do estudo, criação de valor (EVA) e reputação corporativa (REP), realizou-se a Análise de Correspondência (Anacor) para verificar uma primeira associação entre as duas variáveis, utilizando os seus quartis para categorização. Com um $\chi^{2}$ de 19,95 e significância de 0,0182, a criação de valor e a reputação corporativa possuem associação. Dessa forma, o Gráfico 1 apresenta a associação entre as categorias das variáveis criação de valor e reputação corporativa. 
Gráfico 1 - Mapa perceptual

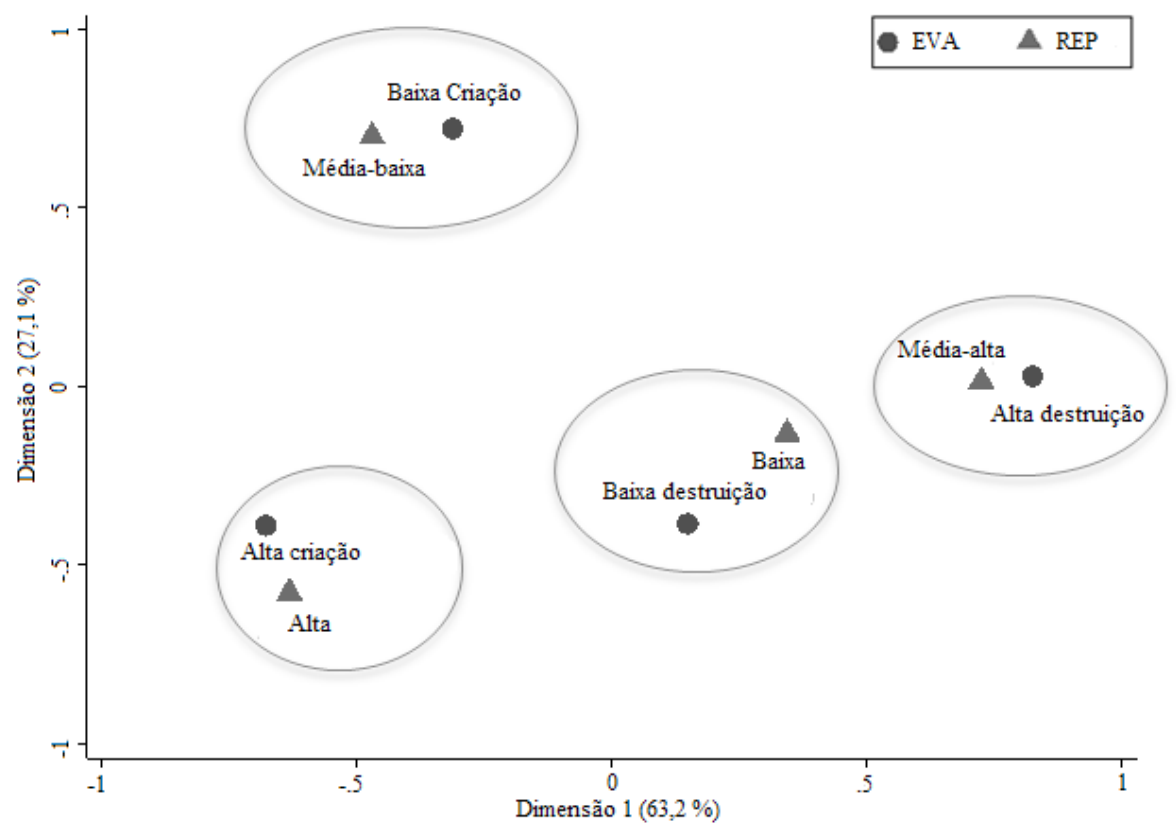

Fonte: os autores.

Nota-se que as empresas tidas com alta reputação estão associadas com as empresas que criam mais valor (EVA). Por sua vez, empresas com média-alta reputação estão associadas com alta destruição de valor, visto que tal resultado seria esperado para empresas de baixa reputação. Já empresas categorizadas como média-baixa reputação possuem baixa criação de valor, e empresas assimiladas com baixa reputação estão associadas à baixa destruição de valor.

Posterior a essa análise, realizou-se a análise de Correlação de Pearson (Tabela 2) para verificar as relações existentes entre as variáveis do estudo. 
Tabela 2 - Correlação de Pearson

\begin{tabular}{|c|c|c|c|c|c|c|c|c|}
\hline & EVA & REP & ROT & END & RIS & IDA & TAM & SET \\
\hline EVA & 1 & & & & & & & \\
\hline REP & 0,0977 & 1 & & & & & & \\
\hline ROT & 0,0219 & 0,0803 & 1 & & & & & \\
\hline END & $-0,3645^{* * *}$ & $-0,0128$ & $-0,0886$ & 1 & & & & \\
\hline RIS & $-0,1775^{* *}$ & $-0,0398$ & $0,2172 * *$ & $0,238 * * *$ & 1 & & & \\
\hline IDA & 0,1225 & $-0,0376$ & 0,0339 & $0,2188^{* *}$ & 0,0886 & 1 & & \\
\hline TAM & $-0,1186$ & $-0,0754$ & $-0,1024$ & $0,2977 * * *$ & $0,1637^{*}$ & 0,1384 & 1 & \\
\hline SET & $-0,078$ & $-0,118$ & $-0,2617 * * *$ & $-0,1753^{* *}$ & $-0,0979$ & $-0,0248$ & $-0,041$ & 1 \\
\hline
\end{tabular}

Nota: ${ }^{(* *)}$ significância até $1 \%$; ${ }^{(* *)}$ significância até 5\%; ${ }^{* *}$ significância até $10 \%$.

Observa-se que apenas endividamento (END) e risco (RIS) possuem uma relação significativa com a criação de valor (EVA), sendo uma relação inversa. Nota-se que, individualmente, a reputação corporativa (REP) não possui relação com a criação de valor, divergindo do resultado encontrado na Anacor. Outras relações podem ser verificadas entre as variáveis de controle, as relações positivas são: risco (RIS) com rotatividade dos empregados (ROT); risco (RIS) com endividamento (END); idade (IDA) com endividamento (END); tamanho (TAM) com endividamento (END); e tamanho (TAM) com risco (RIS). Por sua vez, as relações negativas são: setor de alto impacto ambiental (SET) com rotatividade dos empregados (ROT) e com endividamento (END).

Por último, procedeu-se à Regressão Linear Múltipla, com erros robustos, para atender ao objetivo com este estudo, e, assim, testar a hipótese proposta, conforme a Tabela 3 . 
Tabela 3 - Regressão Linear Múltipla

\begin{tabular}{|c|c|c|c|c|}
\hline Criação de valor & EVA & Coef. Robustos & Erros padrões & Significância \\
\hline Reputação corporativa & REP & 0,0191804 & 0,0074283 & $0,011 * *$ \\
\hline $\begin{array}{l}\text { Rotatividade dos } \\
\text { empregados }\end{array}$ & ROT & $-0,9251193$ & 1,218862 & 0,449 \\
\hline Endividamento & END & $-0,2537177$ & 0,1038656 & $0,016^{* *}$ \\
\hline Risco & RIS & $-0,5404041$ & 0,6126585 & 0,380 \\
\hline Idade & IDA & 0,0183816 & 0,0083108 & $0,029 * *$ \\
\hline Tamanho & TAM & $-0,0251262$ & 0,1396923 & 0,858 \\
\hline $\begin{array}{l}\text { Setor de impacto am- } \\
\text { biental }\end{array}$ & SET & $-0,8338545$ & 0,4903524 & $0,092 *$ \\
\hline Constante & & 1,736155 & 2,214581 & 0,435 \\
\hline $\begin{array}{ll}\text { Obs. } & 126\end{array}$ & $3,05 * *$ & 0,2181 & $\mathrm{R}^{2}$ ajust. $\quad 0,1718$ & VIF médio \\
\hline
\end{tabular}

Com base na Tabela 3, verifica-se, por meio do F-valor, que o modelo é significante a $1 \%$, e que o poder explicativo do modelo é considerado baixo, segundo o $\mathrm{R}^{2}$ ajustado, pois apenas $17,18 \%$ das variáveis em estudo explicam a criação de valor.

Quanto ao modelo da pesquisa, que tem como variável dependente a criação de valor (EVA) e como variável independente a reputação (REP), verifica-se que a reputação corporativa (REP) demonstrou uma relação positiva com a criação de valor (EVA), com significância de até 5\%. Pode-se inferir, portanto, que quanto maior a reputação corporativa, medida pelos sinais propostos no estudo, maior a criação de valor. Observam-se também as variáveis de controle endividamento (END), idade (IDA) e setor de impacto ambiental (SET), obtendo significância de 5\%, 5\% e 10\%, respectivamente, em que, quanto menor o endividamento, maior a idade e não ser de setor de alto impacto ambiental, maior a criação de valor.

Sendo o indicador EVA uma variável que exprime a criação de valor e demonstra também o desempenho das empresas da amostra, pode-se afirmar que a relação positiva entre a reputação corporativa e a criação de valor encontrada no presente estudo é corroborada pelos resultados obtidos por Brito (2005), Cardoso et al. (2013), Fombrun e Shanley (1990), Roberts e Dowling (2002), Sánchez e Sotorrío (2007), Thomaz e Brito (2010) e Tischer e Hildebrandt (2013), que também verificaram haver uma relação positiva entre a reputação e o desempenho empresarial.

Nessa mesma perspectiva, os resultados da pesquisa refutam os estudos de Inglis, Morley e Sammut (2006), Rose e Thomsen (2004) e Wang (2014), pois não encontraram relação entre a reputação corporativa das empresas e o seu desempenho. 
Destarte, não se rejeita a hipótese $\left(\mathrm{H}_{1}\right)$ de que a reputação corporativa influencia positivamente a criação de valor das empresas de capital aberto listadas na BM\&FBovespa. Esse resultado confirma os preceitos de Van Riel e Fombrun (2007) e Walker (2010), de que a reputação fortalece a atratividade de uma organização; atrai e retém colaboradores; cria desempenho financeiro sustentável, maiores margens e preços e valor percebido; além de atrair novas fontes de capital financeiro, reduzindo a situação de risco. Esses fatores desencadeiam a vantagem competitiva, criando heterogeneidade entre as empresas e gerando valor para os stakeholders (BRITO, 2005; MELO; GARRIDO-MORGADO, 2012; ROBERTS; DOWLING, 2002).

Portanto, o resultado está alinhado com os preceitos da VBR, segundo a qual, em um ambiente competitivo, as empresas estão focadas nos recursos estratégicos que são fontes de vantagem competitiva e têm como reflexo o desempenho superior e a criação de valor (BARNEY, 1991; PETERAF, 1993; RIBEIRO; ROSSETTO; VERDINELLI, 2011). Assim, a reputação corporativa, considerada neste estudo um ativo intangível, é um recurso estratégico capaz de gerar visibilidade e credibilidade e é fonte de vantagem competitiva, tendo como reflexo a criação de valor para as organizações que a possuem (FOMBRUN; SHANLEY, 1990; ROBERTS; DOWLING, 2002; THOMAZ; BRITO, 2010).

\section{CONCLUSÃO}

Em conformidade com a problematização da pesquisa, seu objetivo geral consistiu em investigar a relação entre a reputação corporativa e a criação de valor nas empresas de capital aberto listadas na BM\&FBovespa. Para a construção da reputação corporativa, neste estudo adotaram-se sinais que as empresas emitem voluntariamente ou não ao mercado e que possuem a capacidade de alterar a percepção que os stakeholders possuem da empresa, a saber: o disclosure socioambiental, a governança corporativa, a inovação, a internacionalização e a reputação do diretor executivo.

Para atender ao objetivo geral e testar a hipótese de pesquisa $\left(\mathrm{H}_{1:}\right.$ a reputação corporativa influencia positivamente a criação de valor nas empresas), realizou-se a Regressão Linear Múltipla, constatando-se que a reputação corporativa - entendida como as diversas perspectivas que os stakeholders possuem da empresa, atribuindo-lhe a característica de um recurso estratégico capaz de gerar visibilidade, credibilidade e valor para as organizações que a possuem - é capaz de proporcionar às empresas uma maior criação de valor, o que não rejeita a hipótese de pesquisa. Essa relação pode ser explicada a partir da Teoria da Sinalização e da VBR, já que a reputação 
corporativa é gerada pela percepção dos stakeholders por meio dos diversos sinais positivos emitidos para o mercado acerca das atividades desempenhadas pelas empresas, desenvolvendo vantagem competitiva e maior criação de valor.

Verificou-se, portanto, que a reputação corporativa (REP) influencia positivamente a criação de valor (EVA), considerando-se as empresas da amostra. Observou-se, ainda, que os atributos endividamento (END), idade (IDA) e setor de impacto ambiental (SET) devem ser considerados na criação de valor.

Sob a perspectiva teórica, vale ressaltar que os achados da presente pesquisa confirmam as duas teorias utilizadas como suporte. Com efeito, pela ótica da Teoria da Sinalização, pode-se afirmar que as ações das empresas no mercado representam sinais que possibilitam a construção da reputação corporativa e que, considerando-se a VBR, a reputação corporativa, considerada um recurso intangível, desencadeia na vantagem competitiva e cria mais valor para as empresas.

Como contribuição acadêmica, o estudo desenvolveu uma nova variável de reputação corporativa, que tem como base o disclosure socioambiental, a governança corporativa, a inovação, a internacionalização e a reputação do diretor executivo. Sob a perspectiva do mercado de capitais brasileiro, os resultados do estudo revelam a importância de uma boa reputação no mercado e que, portanto, as organizações devem trabalhar na sua construção e/ou manutenção. Para tanto, precisam evidenciar informações de qualidade e tempestivas, em especial quanto ao disclosure socioambiental, à governança corporativa, à inovação e à internacionalização, além de preservar a reputação do diretor executivo, para, assim, auferir os benefícios de uma boa reputação corporativa.

Entre as limitações do estudo, vale citar o período de análise, o número de observações, o caráter voluntário da maioria das informações utilizadas e a métrica de determinadas variáveis. Dessa forma, para pesquisas futuras se sugere o elastecimento do período de análise e de observações, bem como a consideração de métricas distintas para variáveis que representem os sinais. Recomenda-se, ainda, o estudo de outros sinais que possam contribuir para a criação de uma boa reputação corporativa.

\title{
REFERÊNCIAS
}

\author{
ALBANEZ, T. Efeitos do market timing sobre a estrutura de capital de compa- \\ nhias abertas brasileiras. 2012. 257 p. Tese (Doutorado em Controladoria e Con- \\ tabilidade)-Universidade de São Paulo, São Paulo, 2012.
}


ALMEIDA-SANTOS, P. S. et al. Nível de disclosure verde e a reputação corporativa ambiental das companhias brasileiras de capital aberto. Revista Contemporânea de Contabilidade, v. 9, n. 18, p. 63-82, 2012.

BARNETT, M. L.; JERMIER J. M.; LAFFERTY B. A. Corporate reputation: the definitional landscape. Corporate Reputation Review, v. 9, i. 1, p. 26-38, 2006.

BARNEY, J. B. Firm resources and sustained competitive advantage. Journal of Management, v. 17, i. 1, p. 99-120, 1991.

BERGH, D. D. et al. New frontiers of the reputation - performance relationship: insghts from multiple theories. Journal of Management, v. 36, i. 3, p, 620-632, 2010.

BERGH, D. D.; GIBBONS, P. The stock market reaction to the hiring of management consultants: a signalling theory approach. Journal of Management Studies, v. 48, i. 3, p. 544-567, 2011.

BOYD, B. K.; BERGH, D. D.; KETCHEN JUNIOR, D. J. Reconsidering the reputation-performance relationship: a resource-based view. Journal of Management, v. 36, i. 3, p. 588-609, 2010.

BRITO, E. Reputação e desempenho: uma análise empírica no setor bancário. Revista Economia \& Gestão, v. 5, n. 11, p. 117-142, 2005.

BROOKING, A. Intellectual capital: core asset for the third millennium enterprise. Boston: Thomson Publishing Inc., 1996.

CAIXETA, C. G. F. et al. Reputação corporativa e desempenho econômico-financeiro: um estudo em cinco grandes grupos empresariais brasileiros. Revista Eletrônica de Gestão Organizacional, v. 1, n. 9, p. 86-109, 2011.

CARDOSO, V. I. D. et al. Reputação corporativa nas empresas brasileiras: uma questão relevante para o desempenho empresarial? Revista Contemporânea de Contabilidade, v. 10, n. 21, p. 115-136, 2013.

CERQUEIRA, J. E. A.; SOARES, T. M.; DAVID, M. V. Novas evidências sobre a relação entre a geração de valor ao acionista e o valor de mercado das ações: uma análise em painel comparando o EVA e o MVA no mercado brasileiro. Pesquisa Operacional para o Desenvolvimento, v. 1, p. 1-19, 2009.

COLLIS, J.; HUSSEY, R. Pesquisa em administração: um guia prático para os alunos de graduação e pós-graduação. 2. ed. Porto Alegre: Bookman, 2005. 
CRUZ, C. V. O. A.; LIMA, G. A. S. F. Reputação corporativa e nível de disclosure das empresas de capital aberto no Brasil. Revista Universo Contábil, v. 6, n. 1, p. 85-101, 2010.

DAINELLI, F.; BINI, L.; GIUNTA, F. Signaling strategies in annual reports: evidence from the disclosure of performance indicators. Advances in Accounting, incorporating Advances in International Accounting, v. 29, p. 267-277, 2013.

DALMÁCIO, F. Z. et al. Uma análise da relação entre governança corporativa e acurácia das previsões dos analistas do mercado brasileiro. Revista de Administração Mackenzie - RAM, v. 14, n. 5, p. 104-139, 2013.

DAL-SOTO, F.; SANTOS, M. R. Os recursos como fonte de estratégia competitiva: uma evidência empírica da resource-based view. Revista Capital Científico, v. 2, n. 1, p. 47-64, 2004.

DÍEZ, J. M. et al. Intellectual capital and value creation in Spanish firms. Journal of Intellectual Capital, v. 11, i. 3, p. 348-367, 2010.

EHRBAR, A. EVA ${ }^{\circledR}$ : the real key to creating wealth. New York: John Wiley \& Sons, 1999.

FOMBRUN, C. List of Lists: a compilation of international corporate reputation rating. Corporate Reputataion Review, v. 10, i. 2, p. 144-153, 2007.

FOMBRUN, C.; SHANLEY, M. What's in a name? Reputation building and corporate strategy. Academy of Management Journal, v. 33, i. 2, p. 233-258, 1990.

GORGA, E. A cultura brasileira como fator determinante na governança corporativa e no desenvolvimento do mercado de capitais. Revista de Administração USP, v. 39, n. 4, p. 309-326, 2004.

GOTSI, M.; WILSON, A. M. Corporate reputation: seeking a definition. Corporate Communications, v. 6, i. 1, p. 24, 2001.

HALL, A. T. et al. Leader reputation and accountability in organizations: implications for dysfunctional leader behavior. The leadership Quartely, v. 15, p. 515-536, 2004.

HANCOCK, J. I. et al. Meta-analytic review of employee turnover as a predictor of firm performance. Journal of Management, v. 39, i. 3, p. 573-603, 2013. 
HOCHWARTER, W. A. et al. Reputation as a moderator of political behavior-work outcomes relationships: a two-study investigation with convergent results. Journal of Applied Psychology, v. 92, i. 2, p. 567-576, 2007.

INGLIS, R.; MORLEY, C.; SAMMUT, P. Corporate reputation and organizational performance: an Australian study. Managerial Auditing Journal, v. 21, i. 9, p. 934947, 2006.

KAYO, E. K. et al. Ativos intangíveis, ciclo de vida e criação de valor. RAC - Revista de Administração Contemporânea, v. 10, n. 3, p. 73-90, 2006.

KLANN, R. C.; BEUREN, I. M. Características de empresas que influenciam o seu disclosure voluntário de indicadores de desempenho. Brazilian Business Review BBR, v. 8, n. 2, p. 96-118, 2011.

KOCH, P. D.; SHENOY, C. The information contente of dividends and capital structure policies. Financial Management, v. 28, i. 4, p. 16-35, 1999.

LAMEIRA, V. J. As relações entre governança e risco nas companhias abertas brasileiras. Revista Brasileira de Gestão de Negócios, v. 14, n. 42, p. 7-25, 2012.

LAMEIRA, V. J. et al. Is the quality of corporate governance associated with the market risk for Brazilian energy companies? International Journal of Intercultural Information Management, v. 2, i. 4, p. 276-300, 2011.

LEV, B. Intangibles: management, measurement and reporting. Washington: The Brooking Institure, 2001.

LOCKETT, A.; THOMPSON, S.; MORGENSTERN, U. The development of the resource-based view of the firm: a critical appraisal. International Journal of Management Review, v. 11, i. 1, p. 9-28, 2009.

LOPES, A. B.; MARTINS, E. Teoria da contabilidade: uma nova abordagem. São Paulo: Atlas, 2012.

MACHADO, D. D. P. N.; CARVALHO, L. C. Ambiente favorável ao desenvolvimento de inovações: proposição de um modelo de análise organizacional. Revista de Administração USP, v. 48, n. 3, p. 592-607, 2013.

MATOS, J. A. Theoretical foundations of corporate finance. Princeton: Princeton University Press, 2001. 
MELO, T.; GARRIDO-MORGADO, A. Corporate reputation: a combination of social responsibility and industry. Corporate Social Responsibility and Environmental Management, v. 19, i. 1, p. 11-31, 2012.

MICHELON, G. Sustainability disclosure and reputation: a comparative study. Corporate Reputation Review, v. 14, i. 2, p. 79-96, 2011.

MÚRCIA, F. D.-R.; SANTOS, A. Fatores determinantes do nível de disclosure voluntário de companhias abertas no Brasil. Revista de Educação e Pequisa em Contabilidade, v. 3, n. 2, p. 72-95, 2009.

NARDI, P. C. C.; NAKAO, S. H. Impacto da entrada nos níveis diferenciados de governança corporativa sobre a imagem institucional das empresas. Revista Contabilidade Vista e Revista, v. 19, n. 2, p. 85-111, 2008.

NIAP, D. T. F.; TAYLOR, D. CEO personal reputation: does it affect remuneration during times of economic turbulence? Procedia Economics and Finance, v. 2, p. 125-134, 2012.

PETERAF, M. A. The cornerstones of competitive advantage: a resource-based view. Strategic Management Journal, v. 14, i. 3, p. 179-191, 1993.

RIBEIRO, R.; ROSSETTO, C. R.; VERDINELLI, M. A. Comportamento estratégico da empresa e a visão baseada em recursos: um estudo no setor varejista de material de construção. Revista de Gestão \& Produção, v. 18, n. 1, p. 175-192, 2011.

RINDOVA, V. P.; WILLIAMSON, I. O.; PETKOVA, A. P. Reputation as an intangible asset: reflections on theory and methods in two empirical studies of Business School Reputations. Journal of Management, v. 36, i. 3, p. 610-619, 2010.

ROBERTS, P. W.; DOWLING, G. R. Corporate reputation and sustained superior financial performance. Strategic Management Journal, v. 23, i. 12, p. 1077-1093, 2002.

ROSE, C.; THOMSEN, S. The impact of corporate reputation on performance: some Danish evidence. European Management Journal, v. 22, i. 2, p. 201-210, 2004.

ROVER, S. et al. Divulgação de informações ambientais nas demonstrações contábeis: um estudo exploratório sobre o disclosure das empresas brasileiras pertencentes a setores de alto impacto ambiental. Revista de Contabilidade e Organizações - RCO, v. 3, n. 2, p. 53-72, 2008. 
SAMPIERI, R. H.; COLLADO, C. F.; LÚCIO, P. B. Metodologia de pesquisa. 3. ed. São Paulo: McGraw Hill, 2013.

SÁNCHEZ, J. L. F.; SOTORRÍO, L. L. The creation of value through corporate reputation. Journal of Business Ethics, v. 76, i. 3, p. 335-346, 2007.

SANTOS, J. G. C.; VASCONCELOS, A. C.; DE LUCA, M. M. M. Perfil da inovação e da internacionalização de empresas transnacionais. RAI - Revista de Administração e Inovação, v. 10, n. 1, p. 198-211, 2013.

SANTOS, J. O.; WATANABE, R. Uma análise da correlação entre o EVA® e o MVA ${ }^{\circledR}$ no contexto das empresas brasileiras de capital aberto. REGE - Revista de Gestão, v. 12, n. 1, p. 19-32, 2005.

SILVA, R. L. M.; NARDI, P. C. C.; PIMENTA JUNIOR, T. O impacto da migração das empresas para os níveis diferenciados de governança corporativa da BM\&FBovespa sobre o risco e o retorno de suas ações. Revista de Administração da UFSM, v. 5, n. 2, p. 222-242, 2012.

SOUZA, M. M.; LUNKES, R. J.; UHLMANN, V. O. Disclosure ambiental das empresas do setor de biocombustíveis com ações listadas na Bovespa: análise das demonstrações financeiras do período de 2004 a 2008. Revista Capital Científico, v. 8, n. 1, p. 93-106, 2010.

SPENCE, M. Job market signaling. The Quartely Journal of Economics, v. 87, i. 3, p. 355-374, 1973.

SPENCE, M. Signaling in retrospect and the informational structure of markets. The American Economic Review, v. 92, i. 3, p. 434-459, 2002.

SPERS, R. G.; WRIGHT, J. R. C. Uma análise das dimensões estratégicas críticas para a internacionalização das empresas brasileiras nos mercados de base da pirâmide (BOP) globais. Brazilian Business Review - BBR, v. 10, n. 2, p. 26-50, 2013.

STAL, E. Internacionalização de empresas brasileiras e o papel da inovação na construção de vantagens competitivas. Revista de Administração e Inovação - RAI, v. 7, n. 3, p. 120-149, 2010.

TEH, C. C.; KAYO, E. K.; KIMURA, H. Marcas, patentes e criação de valor. Revista de Administração Mackenzie, v. 9, n. 1, p. 86-106, 2008. 
TEIXEIRA, E. A.; NOSSA, V. FUNCHAL, B. O índice de sustentabilidade empresarial (ISE) e os impactos no endividamento e na percepção de risco. Revista de Contabilidade e Finanças - USP, v. 22, n. 55, p. 29-44, 2011.

THOMAZ, J. C.; BRITO, E. P. Z. Reputação corporativa: construtos formativos e implicações para a gestão. Revista de Administração Contemporânea, v. 14, n. 2, p. 229-250, 2010.

TISCHER, S.; HILDEBRANDT, L. Linking corporate reputation and shareholder value using the publication of reputation rankings. Journal of Business Research, 2013. Disponível em: <http://dx.doi.org/10.1016/j.jbusres.2013.08.007>. Acesso em: 13 jan. 2014.

TOMS, J. S. Firm resources, quality signals and the determinants of corporate environmental reputation: some UK evidence. British Accounting Review, v. 34, i. 3, p. 257-282, 2002.

VAN RIEL, C. B. M.; FOMBRUN, C. J. Essentials of corporate communications. New York: Routledge, 2007.

VIEIRA, E.; NOVO, J. A estrutura de capital das PME: evidência no mercado português. Revista Estudos do ISCA, v. 4, n. 2, p. 1-16, 2010.

WALKER, K. A systematic review of the corporate reputation literature: definition, measurement, and theory. Corporate Reputation Review, v. 12, i. 4, p. 357-387, 2010.

WANG, C. H. How relational capital mediates the effect of corporate reputation on competitive advantage: evidence from Taiwan high-tech industry. Technological Forecasting and Social Change, v. 82, p. 167-176, 2014.

ZABALA, I. et al. Corporate reputation in professional services firms: reputation management based on intellectual capital management. Corporate Reputation Review, v. 8, i. 1, p. 59-71, 2005.

\section{Agradecimentos}

Ao apoio da Fundação de Amparo à Pesquisa do Estado de São Paulo FAPESP), processo n. 2016/10738-5. 


\section{Como citar este artigo:}

\section{ABNT}

GÓIS, Alan Diógenes et al. Reputação gera valor para os acionistas? Uma análise nas empresas brasileiras. RACE, Revista de Administração, Contabilidade e Economia, Joaçaba: Ed. Unoesc, v. 16, n. 2, p. 523-546, maio/ago. 2017. Disponível em: <http://editora.unoesc.edu.br/index.php/race>. Acesso em: dia/mês/ano.

APA

Góis, A. D., De Luca, M. M. M., Lima, G. A. S. F. de, \& Vasconcelos, A. C. de (2017). Reputação gera valor para os acionistas? Uma análise nas empresas brasileiras. RACE, Revista de Administração, Contabilidade e Economia, 16(2), 523-546. Recuperado em dia/mês/ano, de http://editora.unoesc.edu.br/index.php/race 